\title{
Paradigm change to cost-effective predictive and preventive medicine: individual profiling of healthy vasospastic individuals for targeted prevention as the cost-effective personalised medicine
}

\author{
Olga Golubnitschaja ${ }^{1 *}$, Kristina Yeghiazaryan', Josef Flammer² \\ From EPMA-World Congress 2013 \\ Brussels, Belgium. 20-21 September 2013
}

\begin{abstract}
Paradigm change to cost-effective predictive and preventive medicine

A paradigm change from delayed interventional approaches to cost-effective predictive and preventive medicine presents an innovative concept for advanced healthcare. Early detection of individual predispositions in healthy populations followed by preventive treatments tailored to the person should be committed to the obligations of primary healthcare.
\end{abstract}

\section{Vasospastic Syndrome: definition and symptoms}

Vascular deregulation (VD) or Vasospastic Syndrome is defined as an inappropriate constriction or insufficient dilatation in the microcirculation. Primary VD is highly prevalent in subpopulations of young people and can potentially predispose healthy individuals to severe disorders (neurodegeneration and cancer) being, therefore, particularly attractive for predictive diagnostics and primary prevention in targeted sub-populations [1], namely

- it occurs more frequently in females and is manifested at puberty, moderating with age

- this phenomenon is even more frequent in the Japanese population compared to Caucasians

- usually, academics are more affected by VD

- in addition to clinical signs there is an inborn increased sensitivity to any kind of stress provocation (mechanical, cold, emotion, etc.), altered drug sensitivity, frequently cold extremities, altered sleep behaviour, reduced feeling of thirst but increased smell perception, low blood-

\footnotetext{
* Correspondence: Olga.Golubnitschaja@ukb.uni-bonn.de

'Department of Radiology, Rheinische Friedrich-Wilhelms-University of Bonn, Germany

Full list of author information is available at the end of the article
}

pressure, reduced body-mass-index, more frequent migraine compared to general population

- Compared to the general population, vasospastic individuals tend to have a meticulous personality and successful professional career, Figure 1.

\section{Patient-profiling to diagnose individual predisposition before pathology manifestation}

Clinical observations, sub-cellular imaging and "gene hunting"-investigations provide evidence for vasospasm as a predisposition to glaucoma [3], the second leading cause of blindness in human beings worldwide. Irrespective of glaucoma predisposition, a development of further vasospasm-related pathologies in individuals with (untreated) vasospastic syndrome cannot be excluded. Patient-profiling and predictive blood-tests detecting pathology-specific biomarker-patterns can specify individual predisposition for effective prevention at low cost.

\section{Patient-profiling for positive and negative prediction of pathology development}

Whereas positive prediction for patients at high risk is important to recognize the pathology before it manifests and at early stages, the negative prediction for individuals at low risk help to avoid undesirable treatments and invasive approaches in the case of non-predisposed individuals. Individual patient profiles are utilised for patient modeling and risk assessment. Blood tests utilizing "omics"-technologies are useful for creating accurate non-invasive positive/negative predictive approaches (Figure 2) [4]. 


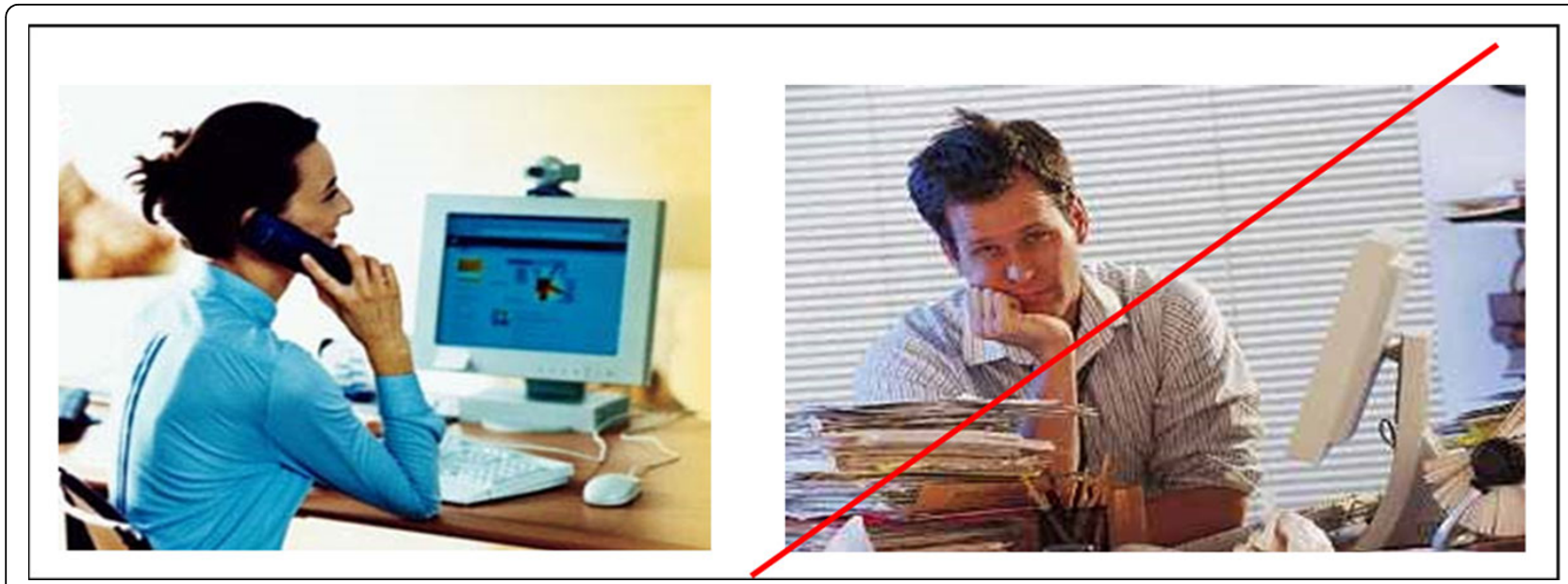

Figure 1 Symptoms and typical attitude of individuals with Vasospastic Syndrome: individuals with primary vasospastic deregulation tend to a meticulous personality and successful professional career such as the young female on the left image [2]

\section{Conclusions and expert recommendations}

- The expression similarities between glaucoma and VD versus controls indicate, on one hand, a predisposition of VD individuals to glaucomatous damage, and, on the other hand, an important role of a vascular component in glaucoma pathology.

- Expression dissimilarities between VD and glaucoma patients might indicate some glaucoma-specific

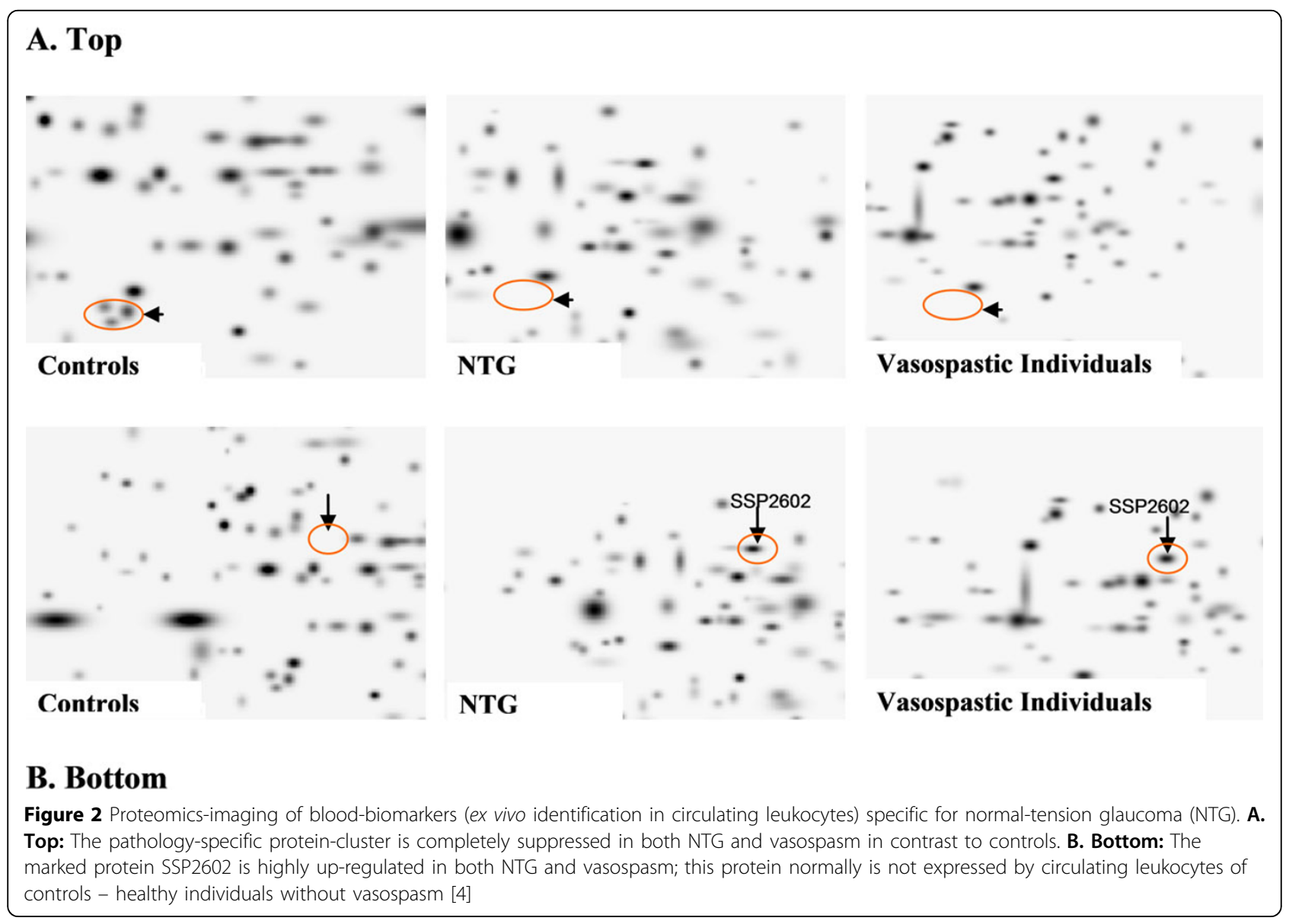


pathomechanisms that are not involved in the stage of predisposition by VD.

- Both expression similarities and dissimilarities could be useful in ascertaining the diagnosis of glaucoma, positive and negative prediction.

- Molecular rearrangement in leukocytes of both VD and glaucoma patients has been shown to be typical for circulating leukocytes during vascular injury and includes an up-regulated adhesive protein expression via ICAM1, an induced chemo-taxis via P2Y purinoceptors, a mobilisation of intracellular $\mathrm{Ca}^{2+}$ response via $\mathrm{Na}$ ${ }^{+} / \mathrm{Ca}^{2+}$ exchanger, and the core of tissue remodelling metalloproteinases.

- Pathology-specific molecular and sub-cellular patterns may create the basis for the development of more specific and non-invasive molecular imaging technologies in early/predictive glaucoma diagnostics.

- Development of some other "down-stream" pathologies different from glaucoma but related to primary vasospastic syndrome cannot be excluded and should be investigated through well designed large-scaled studies.

- Predictive molecular-profiling in blood can specify individual predisposition for effective prevention to low costs [5].

\section{Authors' details}

${ }^{1}$ Department of Radiology, Rheinische Friedrich-Wilhelms-University of Bonn, Germany. ²Department of Ophthalmology, University Hospital Basel,

Switzerland.

Published: 11 February 2014

\section{References}

1. Mozaffarieh M, Fraenkl S, Konieczka K, Flammer J: Targeted preventive measures and advanced approaches in personalised treatment of glaucoma neuropathy. EPMA J 2010, 1:229-236.

2. Flammer J, Pache $M$, Resink T: Vasospasm, its role in the pathogenesis of diseases with particular reference to the eye. Prog Retin Eye Res 2001, 20:319-349.

3. Yeghiazaryan K, Flammer J, Orgül S, Wunderlich K, Golubnitschaja O: Vasospastic individuals demonstrate significant similarity to glaucoma patients as revealed by gene expression profiling in circulating leukocytes. Mol Vis 2009, 15:2339-2348.

4. Golubnitschaja O, Yeghiazaryan K, Wunderlich K, Schild HH, Flammer J: Disease proteomics reveals altered basic gene expression regulation in leukocytes of glaucoma patients. Proteomics Clin Appl 2007, 1:1316-1323.

5. Yeghiazaryan K, Flammer J, Golubnitschaja O: Individual predispositions in healthy vasospastic individuals: Patient profiling for targeted prevention of "down-stream" pathologies as the cost-effective personalised medicine. In Neurodegenerative Diseases: Integrative PPPM Approach as the Medicine of the Future. Book series: Advances in PPPM, Springer;Mandel S 2013.

doi:10.1186/1878-5085-5-S1-A155

Cite this article as: Golubnitschaja et al:: Paradigm change to costeffective predictive and preventive medicine: individual profiling of healthy vasospastic individuals for targeted prevention as the costeffective personalised medicine. EPMA Journal 2014 5(Suppl 1):A155.

\section{Submit your next manuscript to BioMed Central and take full advantage of:}

- Convenient online submission

- Thorough peer review

- No space constraints or color figure charges

- Immediate publication on acceptance

- Inclusion in PubMed, CAS, Scopus and Google Scholar

- Research which is freely available for redistribution

Submit your manuscript at www.biomedcentral.com/submit
C Biomed Central 